\title{
Effects of environmental factors on key kinetic parameters relevant to pitting corrosion
}

\author{
M. T. Woldemedhin • J. Srinivasan • R. G. Kelly
}

Received: 31 December 2014 / Revised: 2 March 2015 / Accepted: 4 March 2015 / Published online: 18 March 2015

(C) The Author(s) 2015. This article is published with open access at Springerlink.com

\begin{abstract}
Experiments using stainless steel artificial pit (leadin-pencil) electrodes in ferric chloride and lithium chloride solutions were performed in order to determine the effects of key environmental factors such as chloride concentration and $\mathrm{pH}$ of the bulk solution on the central parameters utilized to characterize the pitting phenomenon - the repassivation potential $E_{\mathrm{rp}}$ and the pit stability product under a salt film $(i$. $x)_{\text {saltfilm. }}$. For all the stainless steel alloys studied, a relative independence of the $E_{\mathrm{rp}}$ to the pit depth was observed once sufficient anodic charge had been passed. The pit stability product under a salt film was seen to be largely insensitive to the $\mathrm{pH}$ of the bulk solution. $E_{\mathrm{rp}}$, on the other hand, was fairly independent of bulk $\mathrm{pH}$ only at the lower chloride concentrations of both lithium chloride and ferric chloride solutions. The two parameters were affected differently by variation in the chloride concentration of the bulk solutions. Increasing the chloride concentration resulted in a decrease in the value of $(i \cdot x)_{\text {saltfilm }}$ for all alloys in both solutions. In ferric chloride, the value of $E_{\mathrm{rp}}$ increased with increasing chloride concentration for Custom 465 and the austenitic steels, whereas it decreased across the same range for $17-4 \mathrm{pH}$. These trends were explained qualitatively using solution conductivity and alloying composition arguments. Finally, the results obtained from this study allowed for a rationalization of the phenomenology, enabling a method of measurement of the diffusion coefficient and the concentration at saturation of the "stainless steel cation" within the pit, both of which agreed well with values obtained from the existing literature.
\end{abstract}

Keywords Pitting $\cdot$ Stainless steel $\cdot$ Artificial pit electrode . Repassivation potential

M. T. Woldemedhin · J. Srinivasan • R. G. Kelly $(\bowtie)$

Center for Electrochemical Science and Engineering, Department of

Materials Science and Engineering, University of Virginia,

Charlottesville, VA 22904, USA

e-mail: rgk6y@virginia.edu

\section{Introduction}

Metals and alloys covered by a passive oxide film can undergo pitting corrosion in the presence of aggressive ions such as chloride, resulting in accelerated localized dissolution of the underlying material. The oxidation of the metal creates metal cations within the pit which requires the electromigration of anions like chloride from the bulk solution into the pit to maintain charge neutrality. The metal cations from the anodic dissolution undergo hydrolysis producing metal hydroxide(s) and hydrogen ions, which results in an acidic pit solution aggressive enough to depassivate the material by destabilizing the passive film in that localized solution, leading to propagation of pits [1-3].

Pit propagation is an inherently unstable process. In order for the pit to continue growing, the surface of the pit must dissolve rapidly enough to preserve this critical solution within the pit against dilution via diffusion. Sufficient dilution of the pit solution will lead to repassivation. Two critical conditions have been proposed to characterize pit stability: the repassivation potential, $\left(E_{\mathrm{rp}}\right)$, and the pit stability product, $(i \cdot x)$.

$E_{\mathrm{rp}}$ is defined as the potential below which pits can no longer propagate, and thus, any existing pits will repassivate. It represents the condition under which the dissolving pit does not have sufficient overpotential to dissolve rapidly enough to prevent dilution of the pit solution by diffusion. Although first proposed in 1963 [4], the utility of $E_{\mathrm{rp}}$ as a stability criterion was a matter of intense debate [5-9]. Its apparent dependence on experimental parameters [7-10] led to its abandonment for many years as it was seen as not being a reliable material property. Extensive work from several groups [11-16] showed that when a sufficiently large anodic charge was passed during localized corrosion, the repassivation potential attains a value which is independent of charge passed for pit growth. Sridhar et al. [15] demonstrated via extremely longterm ( $>5$ years) potentiostatic tests that this plateau potential 
serves as an excellent lower bound for pitting corrosion. Samples held above the so-determined $E_{\mathrm{rp}}$ suffered localized corrosion, with higher potentials leading to shorter incubation times, whereas samples held below $E_{\mathrm{rp}}$ did not show any localized corrosion even after extended times. Thus, $E_{\mathrm{rp}}$ has been proposed as useful for the long-term prediction of pitting corrosion.

In the 1970s, Galvele [1] used mass transport analysis to show that for a one-dimensional pit to maintain a given concentration of metal ions at its surface, the pit stability product $(i \cdot x)$ must exceed a critical value. In this parameter, $i$ is the anodic dissolution current density at the base of the pit and $x$ is the depth of the one-dimensional pit. It is the depth of the pit that represents the diffusion barrier. Thus, deeper pits can survive with smaller anodic current densities compared to shallower pits [17-21].

One way in which the pit stability product can be determined is via the measurement of the diffusion-limited dissolution rate in the presence of a salt film of the metal salt. Practically, this can be accomplished via the use of an artificial pit, or lead-in-pencil electrode. Beck [22] was one of the earliest adopters of this process in his work on pitting corrosion of titanium rods. Since that time, it has been used by a number of investigators, especially by Newman and coworkers who used it to study the localized dissolution kinetics, salt films, and pitting potentials of 302 and 316 stainless steel samples over a range of experimental conditions to better understand the mechanisms controlling pitting [20].

Work by different authors has focused on the dependence of $E_{\mathrm{rp}}$ and $(i \cdot x)$ on different factors such metallurgical composition [23-30], temperature [13, 31-34], bulk electrolyte composition [13, 29, 32-38], and $\mathrm{pH}[33,34]$. In the present work, a systematic study of the dependence of the pit stability product under a salt film and repassivation potential of four stainless steels (304, 316L, 17-4PH, and Custom 465) on bulk chloride concentration and $\mathrm{pH}$ using the artificial pit technique is described [20, 22]. Moreover, the dependence of the pit stability product under a salt film is shown to allow an experimental determination of the diffusion coefficient and saturation concentration of the metal chloride salts within the pits.

\section{Experimental}

Artificial pit method for $\mathrm{E}_{\mathrm{rp}}$ and (i $\mathrm{x}$ ) determination

The repassivation potential $\left(E_{\mathrm{rp}}\right)$ and pit stability product un-

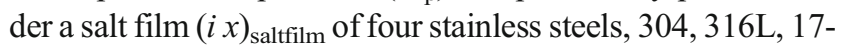
$4 \mathrm{PH}$, and Custom 465, were determined in ferric chloride and acidified lithium chloride solutions using the artificial pit electrode technique. Table 1 shows the chemical composition of the wires tested. The diameter of the 304- and 316-L wire samples was $50 \mu \mathrm{m}$ whereas that of the 17-4PH and Custom
465 samples was $90 \mu \mathrm{m}$. The wires were embedded in epoxy and ground with a 600 grit silicon carbide paper to expose a cross-sectional area. The exposed area of the wire was then rinsed with distilled water and dried with nitrogen gas, before being mounted upright in an electrochemical cell containing either ferric chloride or acidified lithium chloride solution. The electrochemical experiments were carried out in 0.4, $0.6,0.97,1.43,1.8$, and $2.86 \mathrm{M} \mathrm{FeCl}_{3}$ which have $\mathrm{pH}$ values of $1.15,1.0,0.77,0.36,0.3$, and -0.34 , respectively. The same set of experiments was carried out in acidified lithium chloride solutions having the same chloride concentration and $\mathrm{pH}$ as the ferric chloride solutions. Hydrochloric acid was added to adjust the $\mathrm{pH}$ of the lithium chloride solutions to that of the ferric chloride solution of similar chloride concentration. Each electrochemical experiment started by applying $+750 \mathrm{mV}$ versus SCE potentiostatically for $5,10,15,20,30,45,60$, or $120 \mathrm{~min}$ to grow one-dimensional pits of different depths. After each potentiostatic hold, the potential was scanned at a rate of $1 \mathrm{mV} \mathrm{s}^{-1}$ in the cathodic direction.

In this way, the pit stability product and the repassivation potential of the steel samples could be determined from the same experiment. The potential at which the current changed polarity was taken as the repassivation potential of the sample for that pit depth and bulk environment. The value of $(i x)_{\text {saltfilm }}$ was determined from an analysis of the current density plateau at high potentials as shown in Fig. 1. This plateau is the diffusion-limited current density of the metal dissolution at the base of the pit. The diffusion-limited current density is used to calculate the pit stability product under a salt film based on the following rearrangement of the steady-state diffusion equation $[20,39]$ :

$i_{L} d=n F D \Delta C=(i \cdot x)_{\text {salffilm }}$

where $i_{L}$ is the diffusion-limited current density, $d$ is the depth of pit, $n$ is the number of electrons transferred, $F$ is the Faraday's constant, $D$ is the diffusion coefficient, and $\Delta C$ is the difference in concentration of metal cations between the surface of the pit and the bulk solution. The sum of the anodic charge densities passed during potentiostatic pit growth and subsequent cathodic potentiodynamic scans is directly proportional to the pit depth $d$, given in Eq. 2, based on Faraday's law where $A$ is the mean atomic weight and $\rho$ is the density [40]:

$d=\frac{A}{n F \rho} \int i d t$

The polarization scans were recorded for a series of pit depths, allowing the determination of the repassivation potential and pit stability product under a salt film at different pit depths. 
Table 1 Composition of the stainless steels used (all values in weight percent)

\begin{tabular}{llllllllllllllll}
\hline Alloys & $\mathrm{C}$ & $\mathrm{Mn}$ & $\mathrm{P}$ & $\mathrm{S}$ & $\mathrm{Si}$ & $\mathrm{Cr}$ & $\mathrm{Ni}$ & $\mathrm{Mo}$ & $\mathrm{Ti}$ & $\mathrm{Fe}$ & $\mathrm{Co}$ & $\mathrm{Nb}$ & $\mathrm{Ta}$ & $\mathrm{N}$ & $\mathrm{Cu}$ \\
\hline $304 \mathrm{~L}^{1}$ & .03 & 1.59 & .036 & .0010 & .27 & 18.48 & 9.20 & - & - & 70.26 & .13 & .001 & .001 & .001 & - \\
$316 \mathrm{~L}^{1}$ & .019 & 1.356 & .030 & .0287 & .406 & 17.07 & 10.66 & 2.16 & - & 67.98 & - & - & - & .0499 & 0.232 \\
Custom $^{2} 465^{2}$ & .0047 & .01 & .003 & $<.0005$ & .02 & 11.56 & 10.98 & .92 & 1.56 & 74.94 & - & - & - & - & - \\
$17-4 \mathrm{PH}^{2}$ & .03 & .78 & .022 & .0020 & .49 & 15.26 & 4.58 & 0.42 & - & 75.16 & - & - & - & - \\
\hline
\end{tabular}

${ }^{a}$ California fine wire company

${ }^{\mathrm{b}}$ Fort wayne metals

\section{Results}

Using the method described above, the repassivation potential and pit stability product of steel samples were determined from a single experiment for each pit depth and bulk environment. From the cathodic polarization scans, the diffusionlimited current plateau was used to calculate the $(i x)_{\text {saltfilm }}$ whereas the potential at which the current changed polarity was used as $E_{\mathrm{rp}}$ at that specific pit depth. In this way, the functional dependences of $E_{\mathrm{rp}}$ and $(i x)_{\text {saltfilm were evaluated }}$ with a particular focus on the $\mathrm{pH}$ and chloride ion concentration. Ferric chloride and lithium chloride solutions were used to allow the two dependences to be determined and to assess the dependence of these values on the presence of an oxidizer $\left(\mathrm{Fe}^{3+}\right)$.

$\mathrm{E}_{\mathrm{rp}}$ and (i x $)_{\text {saltfilm }}$ in $\mathrm{FeCl}_{3}$ solutions of different concentration and $\mathrm{pH}$

Figure 1 shows typical cathodic polarization scans after potentiostatic pit growth on 304 and $316 \mathrm{~L}$ in $1.43 \mathrm{M} \mathrm{FeCl}_{3}$ solution. Figure 2 shows plots of the repassivation potential of the four stainless steels studied as a function of the charge density passed during one-dimensional pit growth in ferric chloride solutions. The ferric chloride solutions are acidic with $\mathrm{pH}$ values that depend on ferric chloride concentration. The repassivation potential of the steel samples decreased with increasing anodic charge density passed during pit growth in solutions of different chloride concentration and $\mathrm{pH}$, with the exception of the Custom 465 at high chloride concentrations, for which little dependence on charge density was observed. At sufficiently high charge density, the repassivation potential was seen to become independent of pit depth, attaining a constant value. This repassivation potential value at this plateau was taken as the repassivation potential of the alloy in the environmental conditions under consideration.

As mentioned above, the pit stability product under a salt film was also determined from each experiment. The pit stability product under a salt film was determined from the slope of a plot of the limiting current density versus the inverse of the pit depth in accordance with Eq. 1. Figure 3 shows such plots for the four stainless steels in the different ferric chloride solutions. The linearity of all of the lines in Fig. $3\left(R^{2}\right.$ values were all $>0.992$ ) validates the assumption of diffusion control. In all cases, the pit stability product under a salt film decreased with increasing ferric chloride concentration.

$E_{\text {rp }}$ and $(i \cdot x)_{\text {saltfilm }}$ in acidified $\mathrm{LiCl}$ solutions of different concentration and $\mathrm{pH}$

The same set of experiments was repeated on 304 and $316 \mathrm{~L}$ in acidified lithium chloride solutions as shown in Fig. 4. The
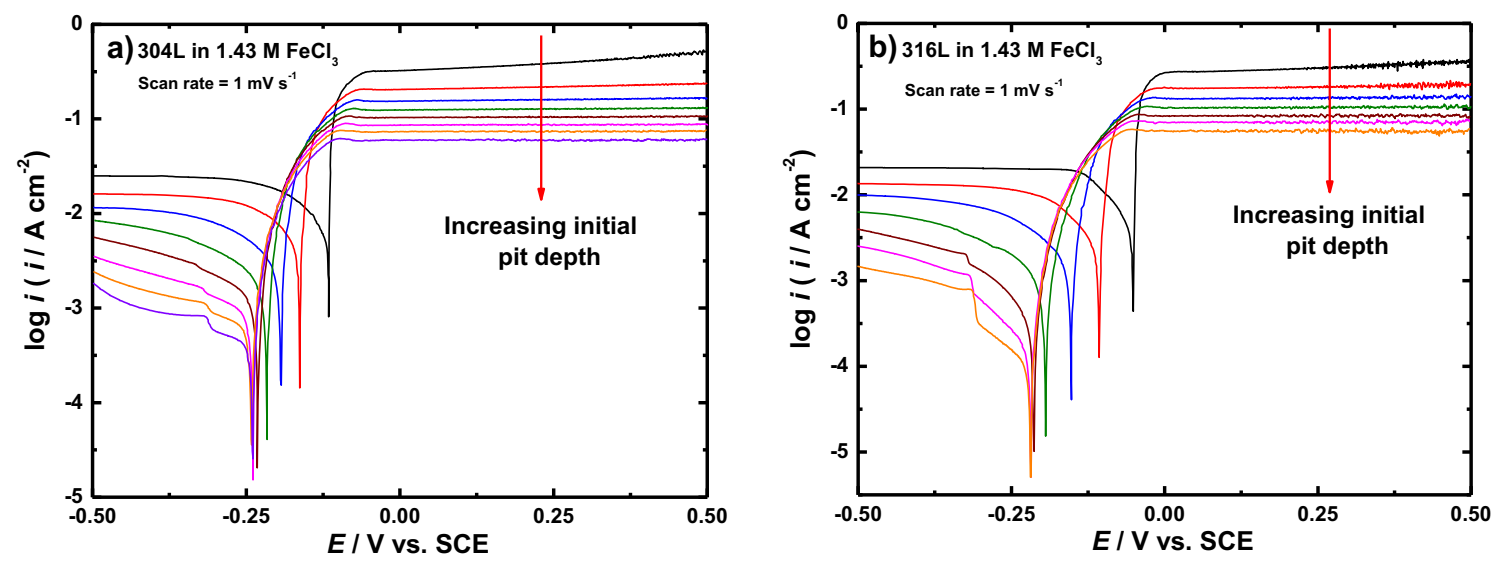

Fig. 1 Cathodic polarization scans after pit growth on $\mathbf{a} 304 \mathrm{~L}$ and $\mathbf{b} 316 \mathrm{~L}$ in $1.43 \mathrm{M} \mathrm{FeCl}_{3}$ at a scan rate of $1 \mathrm{mV} \mathrm{s}^{-1}$ 

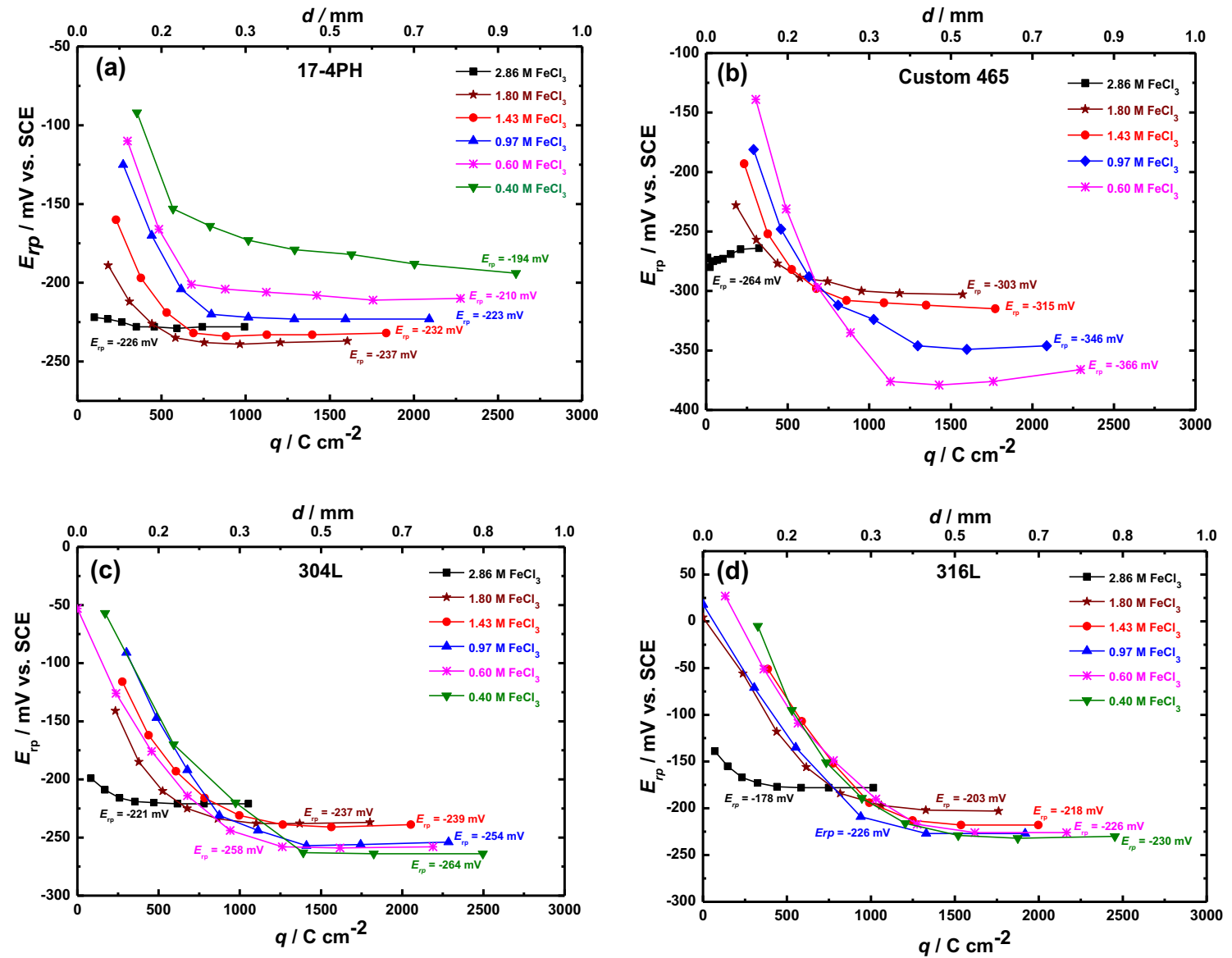

Fig. 2 Repassivation potential of a 17-4PH, b Custom 465, c $304 \mathrm{~L}$, and d $316 \mathrm{~L}$ using the artificial pit method in different $\mathrm{FeCl}_{3}$ solutions

repassivation potentials again reached a constant value at sufficiently large values of anodic charge, but the approach of $E_{\mathrm{rp}}$ to the plateau followed one of two trends as shown in Fig. 5. In 1.2 and $4.29 \mathrm{M} \mathrm{LiCl}$ solutions, the repassivation potential decreased with increasing pit depth as it was expected. However, in 2.91 and $8.58 \mathrm{M} \mathrm{LiCl}$, the trend changed where the repassivation potential increased with pit depth before finally reaching a plateau value.

The pit stability products of 304 and $316 \mathrm{~L}$ in $\mathrm{LiCl}$ solutions were determined from the slopes of Fig. 6 in the same manner as was used for the ferric chloride solutions. As observed in ferric chloride, the pit stability product decreased with increasing salt concentration. The plots are highly linear $\left(R^{2}>0.998\right)$, again validating the use of steady-state diffusion analysis.

Values of the repassivation potential and pit stability product value were also determined for $17-4 \mathrm{PH}$ in $0.6 \mathrm{M} \mathrm{NaCl}$ solution, as shown in Fig. 7. Similar to the above results for 304 and $316 \mathrm{~L}$ in acidic solutions, the repassivation potential of 17-4PH reaches a plateau value after sufficient amount of charge was passed in the growth of the one-dimensional pit. In addition, the limiting current density was linearly related to the reciprocal of the pit depth, giving a value of $0.895 \mathrm{~A} \mathrm{~m}^{-1}$ as the pit stability product of $17-4 \mathrm{PH}$ in $0.6 \mathrm{M} \mathrm{NaCl}$.

\section{Discussion}

Potentiostatic pit growth followed by cathodic polarization scan on one-dimensional electrodes has allowed determination of the repassivation potential and pit stability product of steel samples from a single experiment. The dependence of these parameters on bulk chloride concentration and $\mathrm{pH}$ is discussed in this section. Based on the linear dependence of the pit stability product of the steel samples with the bulk chloride concentration shown above, the diffusion coefficient of the metal cation out of the pit and its saturation concentration were determined. Moreover, the repassivation potentials measured in this work are verified to be the actual repassivation potential of the sample under the specified environment rather than being the equilibrium reversible potential of the ferric-ferrous redox couple.

The phenomenology observed in the experiments was also rationalized in order to extract estimates of the diffusion coefficient and the concentration at saturation of the solution 

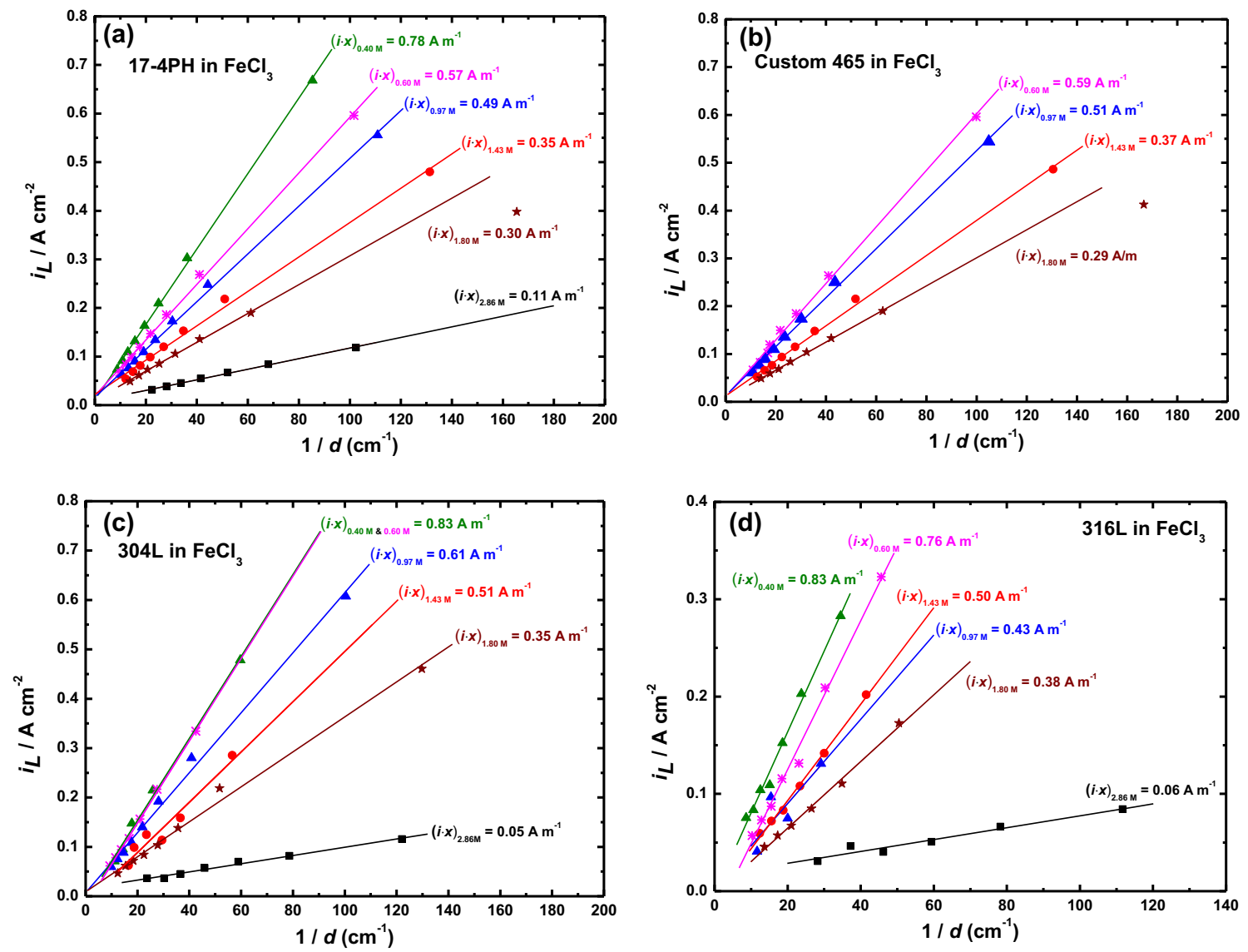

Fig. 3 Plot of limiting current density $\left(i_{L}\right)$ versus inverse of pit depth (1/ d) for a $17-4 \mathrm{PH}, \mathbf{b}$ Custom 465, c $304 \mathrm{~L}$, and d $316 \mathrm{~L}$ (note: the scale is different for $316 \mathrm{~L}$ ) from artificial pit method in $\mathrm{FeCl}_{3}$ solutions of

different concentration and $\mathrm{pH}$ (all values denoted as $(i \cdot x)$ are values for pit stability product under a salt film $\left.(i \cdot x)_{\text {saltfilm }}\right)$

within the pit. These estimates were seen to be comparable to the values obtained from other studies in the literature.

\section{1. $E_{\mathrm{rp}}$ and $(i \cdot x)_{\text {saltfilm }}$}

For all the steels studied in this work, the repassivation potential reaches a plateau value after a sufficient charge density

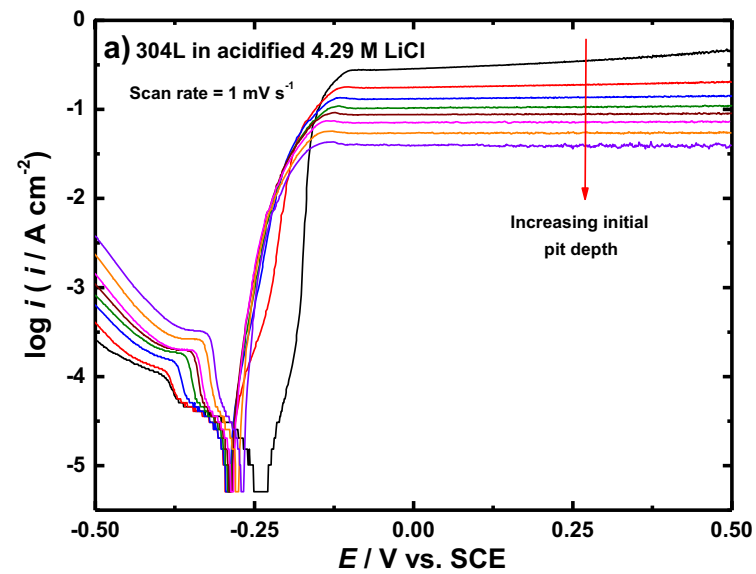

was passed during pit growth. After reaching the plateau value, the repassivation potential becomes invariant of pit depth. Similar reports [16, 34, 41, 42] on different materials showed a similar lack of sensitivity of repassivation potential to pit depth when large amounts of charge were passed to grow the pits and hence defining the lower bound in potential which can sustain pit growth.

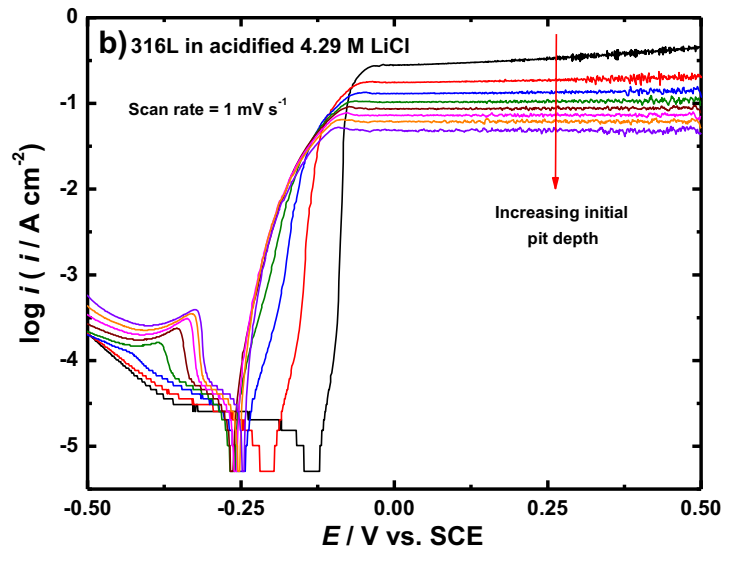

Fig. 4 Typical cathodic polarization scans after potentiostatic pit growth on a $304 \mathrm{~L}$ and b $316 \mathrm{~L}$ in $4.29 \mathrm{M} \mathrm{LiCl}$ acidified to a pH of 0.36 (same chloride concentration and $\mathrm{pH}$ as $1.43 \mathrm{M} \mathrm{FeCl}_{3}$ ) at a scan rate of $1 \mathrm{mV} \mathrm{s}^{-1}$ 

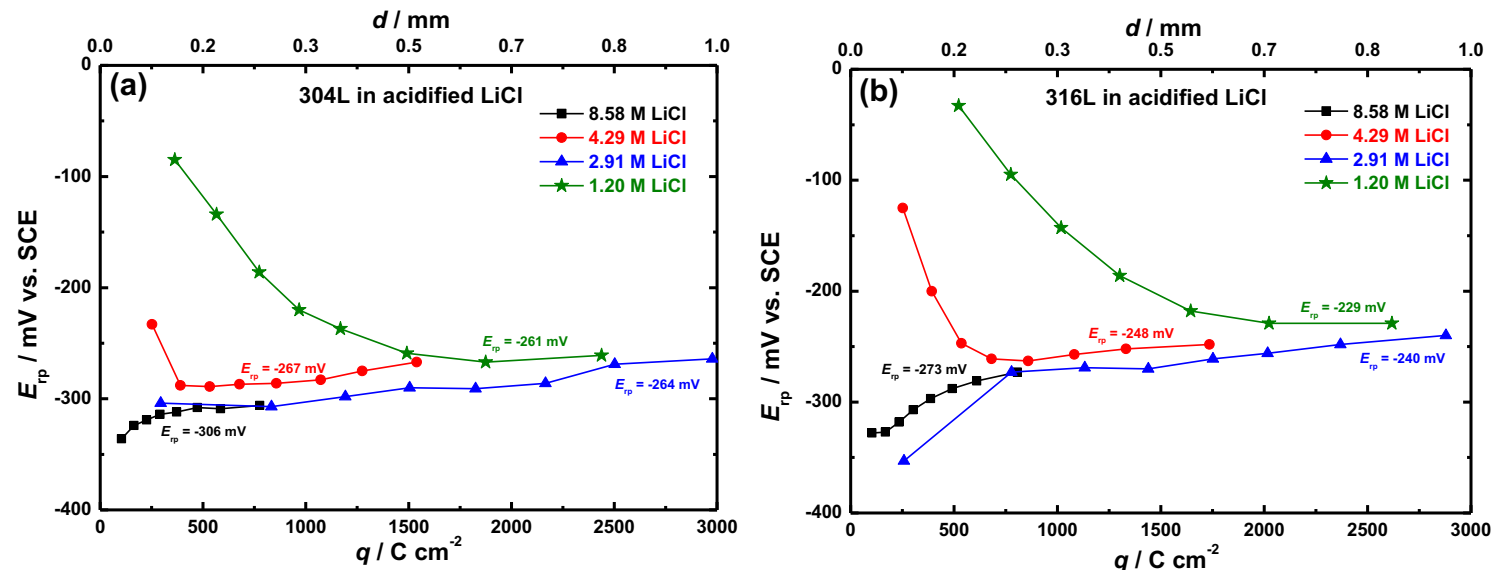

Fig. 5 Repassivation potential of $\mathbf{a} 304 \mathrm{~L}$ and $\mathbf{b} 316 \mathrm{~L}$ using artificial pit method in different $\mathrm{LiCl}$ solutions having equivalent chloride concentration and $\mathrm{pH}$ to $\mathrm{FeCl}_{3}$ solutions used in the above experiments to isolate the effect of $\mathrm{Fe}^{3+}$ ion on $E_{\mathrm{rp}}$

As shown in Fig. 2, the $E_{\mathrm{rp}}$ values of Custom 465, 304, and $316 \mathrm{~L}$ increased with increasing chloride concentration and decreasing $\mathrm{pH}$ of ferric chloride solutions in contrast to the results observed at lower chloride concentrations by others $[15,43,44]$. However, 17-4PH shows the opposite trend with the repassivation potential decreasing with increasing chloride concentration. Contrary to the results in ferric chloride solutions, the repassivation potential of 304 and $316 \mathrm{~L}$ decreases with increasing chloride concentration in $\mathrm{LiCl}$ solutions.

A comparison of the repassivation potential of 304 and $316 \mathrm{~L}$ in the two electrolyte solutions used is shown in Fig. 8. At lower bulk chloride concentrations, the difference in repassivation potential determined in $\mathrm{FeCl}_{3}$ and $\mathrm{LiCl}$ for 304- and 316-L samples is negligible. However, with increasing bulk chloride concentration, the repassivation potential difference in the two electrolytes used reached 85 and $95 \mathrm{mV}$ for 304 and $316 \mathrm{~L}$, respectively, as shown in Fig. 8.

Based on previously reported studies, the repassivation potential is expected to decrease with increasing concentration of

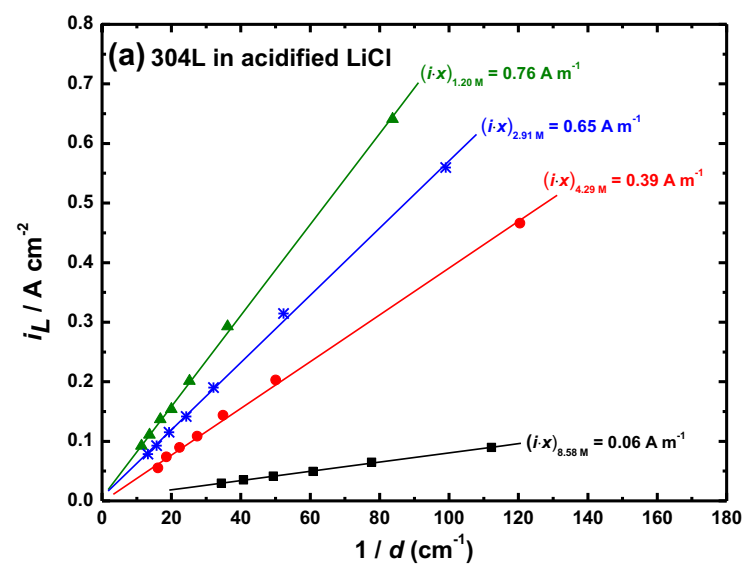

Fig. 6 Plot of limiting current density $\left(i_{L}\right)$ versus inverse of pit depth $(1 /$ d) for a $304 \mathrm{~L}$ and b $316 \mathrm{~L}$ (note: the scale is different for $316 \mathrm{~L}$ ) from artificial pit method in acidified lithium chloride solutions of same chloride ions [37, 45]. This trend was observed for 304 and $316 \mathrm{~L}$ in LiCl. However, the opposite trend-that of $E_{\mathrm{rp}}$ increasing with increasing bulk chloride concentration-was observed for 304, $316 \mathrm{~L}$, and Custom 465 in $\mathrm{FeCl}_{3}$ (data for the austenitic steels shown in Fig. 8). A first attempt at rationalizing these observations may be made using mixed potential theory [46]. Upon increasing the bulk concentration of $\mathrm{FeCl}_{3},\left[\mathrm{Fe}^{3+}\right]$ also increases at the pit surface. As $\left[\mathrm{Fe}^{3+}\right]$ increases, the associated reduction of $\mathrm{Fe}^{+3}$ to $\mathrm{Fe}^{+2}$ would overwhelm proton reduction, thereby assuming the role of the dominant local cathodic reaction. This reaction would become more prominent as $\left[\mathrm{Fe}^{3+}\right]$ increases, resulting in higher diffusion-limited cathodic current densities at higher bulk concentrations of $\mathrm{Fe}^{3+}$ (and congruently, $\mathrm{Cl}^{-}$). Provided that the anodic reaction remains the same throughout, mixed potential theory dictates that the overall effect would be that the measured $E_{\mathrm{rp}}$ increases with increasing bulk $\left[\mathrm{Cl}^{-}\right]$. Close inspection of the polarization curves of $316 \mathrm{~L}$ showed that the diffusion-limited cathodic current densities increased with

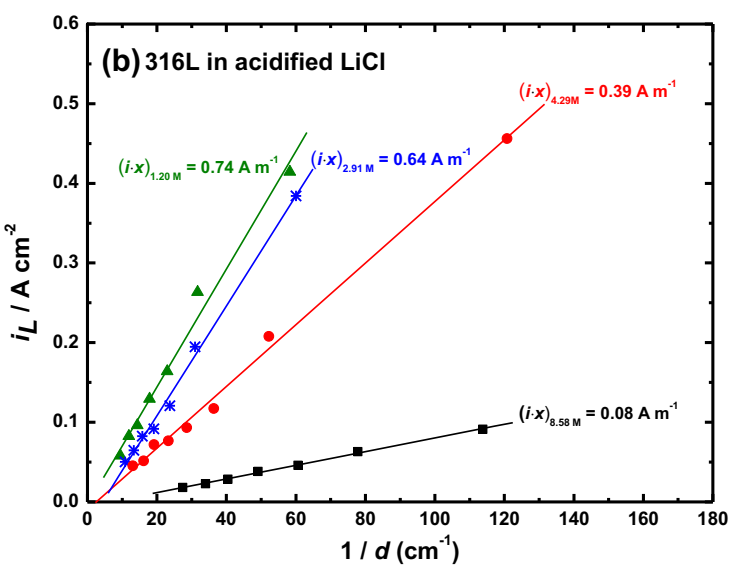

chloride concentration and $\mathrm{pH}$ as the ferric chloride solutions used in the above experiments (all values denoted as $(i \cdot x)$ are values for pit stability product under a salt film $\left.(i \cdot x)_{\text {saltfilm }}\right)$ 

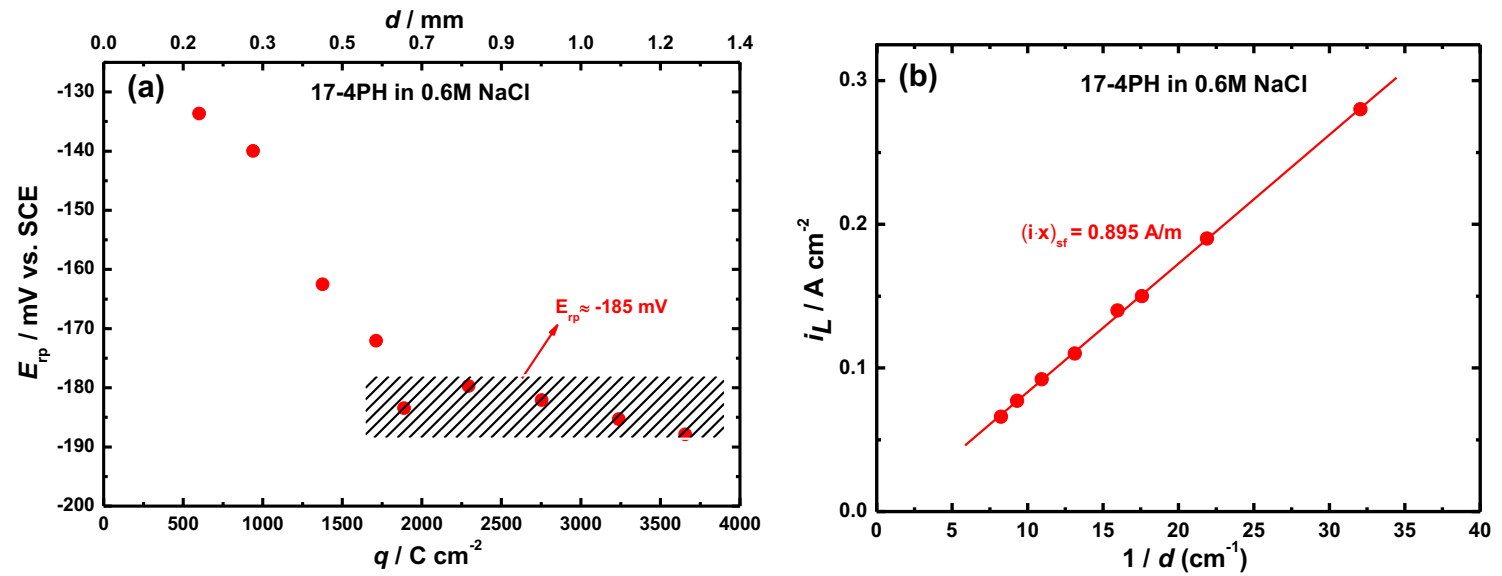

Fig. $7 \mathbf{a} E_{\mathrm{rp}}$ and $\mathbf{b}(i \cdot x)_{\text {saltfilm }}$ of $17-4 \mathrm{PH}$ in a solution of $0.6 \mathrm{M} \mathrm{NaCl}$

increasing $\left[\mathrm{FeCl}_{3}\right]$, but remained the same for the $\mathrm{LiCl}$ solutions, as shown in Fig. 9a. For a given depth, the current density increased with increasing bulk electrolyte concentration. Another point of interest from the figure is that for deeper pits, the difference in current densities across bulk electrolyte concentration became less prominent. Such a trend is likely due to the aggressive solution within the pit facing an increasing mass transport barrier to exit the pit, as diffusion lengths increase. Consequently, the difference in cathodic current densities across bulk electrolyte concentration becomes less prominent because it becomes more difficult for the bulk solution to enter the pit and interact with the electrode surface as the pit depth increases.

In the case of $17-4 \mathrm{PH}$ in $\mathrm{FeCl}_{3}$, the $E_{\mathrm{rp}}$ decreased as the bulk electrolyte concentration increased to $1.8 \mathrm{M}$. A preliminary attempt at rationalizing such behavior can also be performed using mixed potential theory. The local cathodic reaction of interest in the case of 17-4PH would be the reduction of $\mathrm{Cu}^{2+}$ to $\mathrm{Cu}$ due to the presence of copper in the alloy $(\approx 3 \mathrm{wt}$ pct, shown in Table 1). The reduction of $\mathrm{Cu}^{2+}$ to $\mathrm{Cu}$ would proceed at rates high enough to assume the role of the dominant local

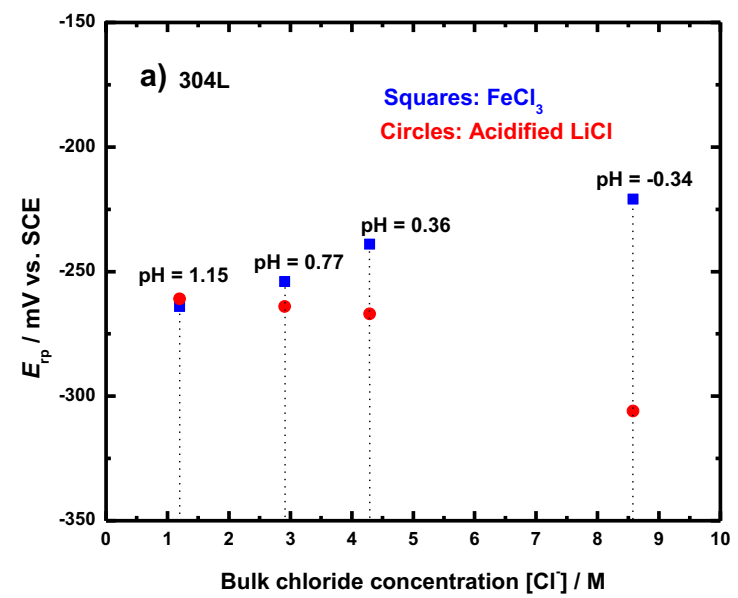

cathodic reaction, overwhelming any effects of $\mathrm{Fe}^{3+} \mid \mathrm{Fe}^{2+}$ reduction arising from the increase in $\left[\mathrm{Fe}^{3+}\right]$ with increasing bulk concentration of $\mathrm{FeCl}_{3}$ as reasoned earlier. Figure $9 \mathrm{~b}$ shows this observation for 17-4PH at various pit depths. The approach of the cathodic current densities to a plateau in the range of 0.5$1.5 \mathrm{M} \mathrm{FeCl}_{3}$, particularly for deeper pits, is a likely indicator of the effect of copper participating in the electrochemistry of the system. There is some evidence in the existing literature for $\mathrm{Fe}-$ $\mathrm{Cr}-\mathrm{Ni}$ alloys with similar levels of copper to that of 17-4PH that display a similar trend in repassivation behavior with bulk electrolyte concentration, with Sridhar and Cragnolino [15] reporting that in their experiments on Alloy 825 (1.5 to $3 \mathrm{wt}$ pct $\mathrm{Cu}$ ) at $95^{\circ} \mathrm{C}$, the repassivation potential of the alloy decreased with increasing bulk chloride concentration. Finally, it is of interest to note that at the highest electrolyte concentration of $2.86 \mathrm{M}$, the cathodic current density approached values close to those of the $\mathrm{Fe}^{3+} \mid \mathrm{Fe}^{2+}$ reduction observed for $316 \mathrm{~L}$ in $\mathrm{FeCl}_{3}$. This behavior may indicate that at the highest bulk $\mathrm{FeCl}_{3}$ concentration, $\mathrm{Fe}^{3+} \mid \mathrm{Fe}^{2+}$ reduction becomes the dominant local cathodic reaction, resulting in the observed increase in $E_{\mathrm{rp}}$ seen in Fig. 2a.

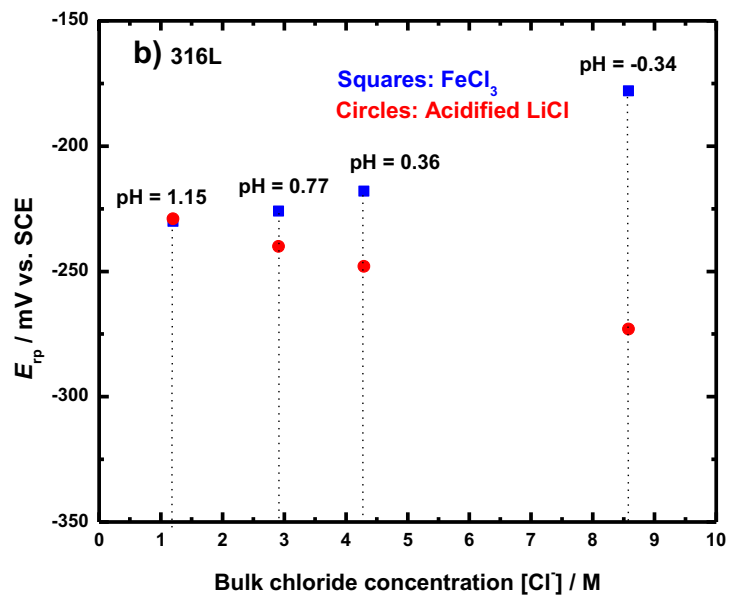

Fig. 8 A comparison of $E_{\mathrm{rp}}$ for $\mathbf{a} 304 \mathrm{~L}$ and $\mathbf{b} 316 \mathrm{~L}$ at the same chloride concentration and $\mathrm{pH}$ in $\mathrm{FeCl}_{3}$ and acidified $\mathrm{LiCl}$ solutions 

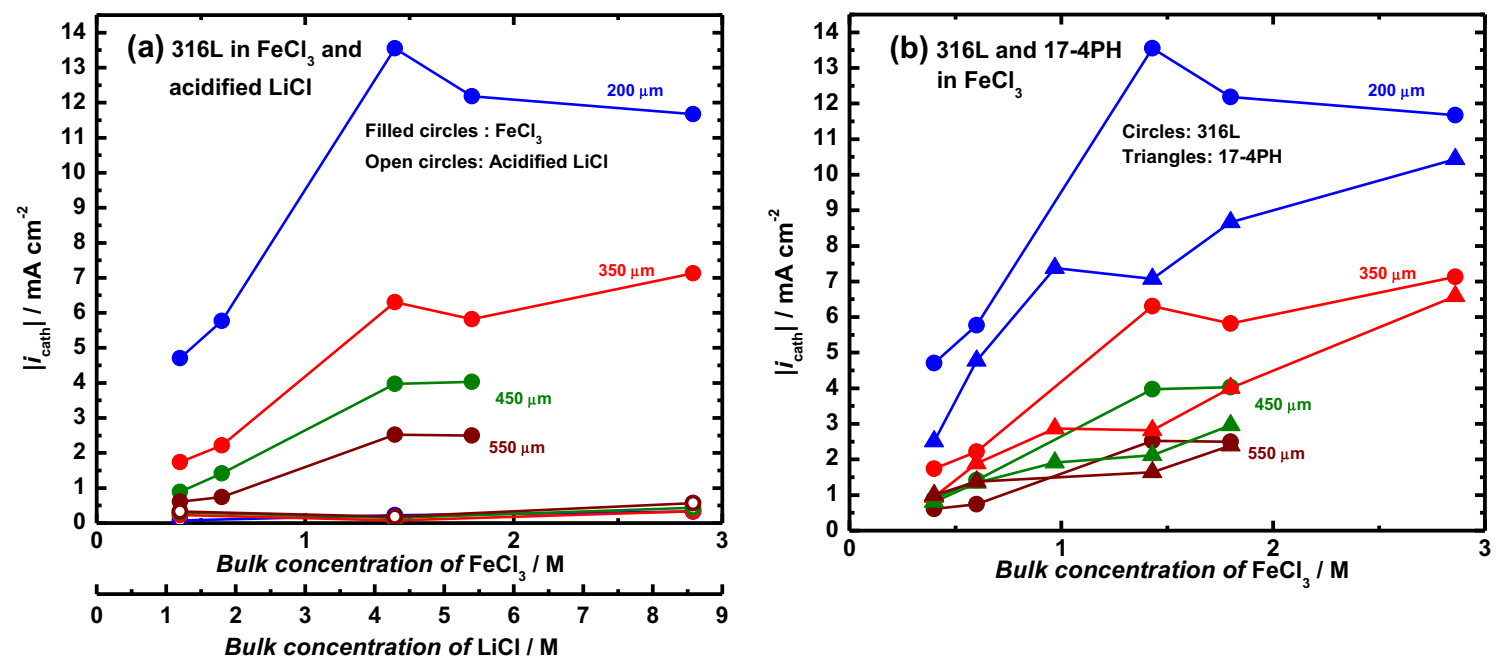

Fig. 9 Variation of cathodic current densities (measured at $-0.5 \mathrm{~V}$ vs SCE) across bulk electrolyte concentration and pit depths for a $316 \mathrm{~L}$ in $\mathrm{FeCl}_{3}$ and acidified $\mathrm{LiCl}$ and $\mathbf{b} 316 \mathrm{~L}$ and $17-4 \mathrm{PH}$ in $\mathrm{FeCl}_{3}$

However, the results obtained for $304 \mathrm{~L}$ and Custom 465 could not be rationalized using arguments similar to those presented above. An overarching explanation for the $E_{\mathrm{rp}}$ behavior across bulk electrolyte concentration would have to take into consideration results obtained for all the four stainless steels in the absence of $\mathrm{Fe}^{3+}$. The change in diffusivity of the ions of interest arising from viscosity effects at higher concentration, as reported by Tester and Isaacs [40], would also have to be accounted for in such an explanation. Finally, as bulk concentration increases, the chloride concentration gradient between the pit base and the bulk disappears and even reverses at very high chloride concentrations. For instance, a bulk $\left[\mathrm{Cl}^{-}\right]$of $8.58 \mathrm{M}$ is greater than the $\left[\mathrm{Cl}^{-}\right]$at the base (assuming a salt film) as estimated from values in the literature [47-49]. This change in concentration gradient would become even more acute when the fact that the critical $\left[\mathrm{Cl}^{-}\right]$at the pit base may be lower than that at saturation [49-52] is considered.

The pit stability product under a salt film decreased with increasing chloride concentration and decreasing $\mathrm{pH}$ for the four steel samples in ferric chloride and lithium chloride solutions for 304 and $316 \mathrm{~L}$ as shown in Figs. 3 and 6. The solubility of the salt film decreased as a result of the increasing bulk chloride concentration. For one-dimensional pits of equal depth, a decrease in the solubility of the metal chlorides in the salt film implies that a smaller anodic dissolution current density is required to maintain the saturation concentration within the pit, which would result in the observation of a lower $(i$.

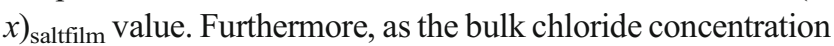
increases, the viscosity of the bulk solution also increases [40]. This viscosity increase would result in lowered diffusion rates, and as a consequence, the coupled anodic dissolution rate and the associated $(i \cdot x)_{\text {saltfilm }}$ value would decrease.

It was mentioned above that the repassivation potential depends on different environmental factors and scan rate of the cathodic polarization scans [15]. In this work, the repassivation potentials were determined at the same scan rate for all the samples. Thus, the only variables which can affect the repassivation potential and pit stability product for a given alloy are either bulk chloride concentration or $\mathrm{pH}$. However, these graphs alone cannot deconvolute the effect of $\mathrm{pH}$ on the $E_{\mathrm{rp}}$ and $(i \cdot x)_{\text {saltfilm }}$ from that of the bulk chloride concentration. In order to do so, experiments were carried out at fixed chloride concentration and scan rate in solutions of different $\mathrm{pH}$ on $316 \mathrm{~L}$, as shown in Fig. 10. As indicated in Fig. 10a, $E_{\mathrm{rp}}=-228 \mathrm{mV}$ vs SCE in all solutions of different $\mathrm{pH}$. Therefore, the bulk electrolyte $\mathrm{pH}$ had no effect on $E_{\mathrm{rp}}$ in the acidic range. Likewise, $(i \cdot x)_{\text {saltfilm }}$ was also seen to have little dependence on bulk $\mathrm{pH}$, as shown in Fig. 10b. Moreover, $E_{\mathrm{rp}}$ and $(i \cdot x)_{\text {saltfilm }}$ of $17-4 \mathrm{PH}$ were determined in $\mathrm{NaCl}$ solution $(\mathrm{pH} \approx 6)$. Figure $7 \mathrm{a}$ shows the $E_{\mathrm{rp}}$ of $17-4 \mathrm{PH}$ in $0.6 \mathrm{M} \mathrm{NaCl}$, measured to be $-185 \mathrm{mV}$ vs SCE. This value was only $10 \mathrm{mV}$ higher than the repassivation potential value of $17-4 \mathrm{PH}$ in $0.4 \mathrm{M} \mathrm{FeCl}_{3}(\mathrm{pH}=1.15)$. The difference in $\mathrm{pH}$ value between $0.6 \mathrm{M} \mathrm{NaCl}$ and $0.4 \mathrm{M} \mathrm{FeCl}_{3}$ is around 6 units, i.e., a change in $\left[\mathrm{H}^{+}\right]$of a factor of $10^{6}$. For such a large change in $\mathrm{pH}$ of the bulk solution, the $E_{\mathrm{rp}}$ changed by only $10 \mathrm{mV}$. Thus, based on the results on Figs. 7 and 10, one can conclude that the repassivation potential is independent of the $\mathrm{pH}$ of the bulk solution. Similar observations were made by Sridhar and Cragnolino [15] and Kehler et al. [34]. The $(i \cdot x)_{\text {saltfilm value }}$ of 17-4PH changed by only $0.1 \mathrm{~A} \mathrm{~m}^{-1}$ for such a large change in $\mathrm{pH}$ value of the bulk electrolyte, thus proving that the pit stability product was also nearly independent of the $\mathrm{pH}$ of the bulk electrolyte.

Experimental determination of $\mathrm{D}_{\mathrm{m}}$ and $\mathrm{C}_{\mathrm{sat}}$

The properties of the salt film and mass transport controlled dissolution of iron and its alloys have been studied in the past 

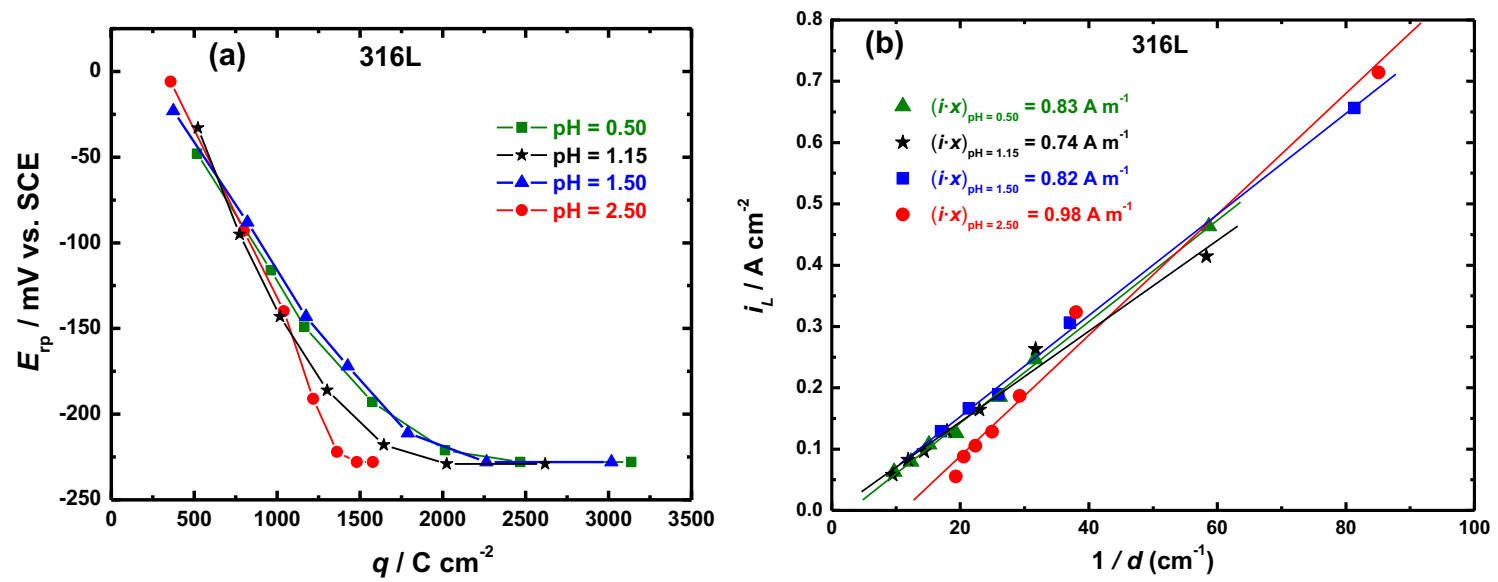

Fig. 10 Effect of $\mathrm{pH}$ on $\mathbf{a} E_{\mathrm{rp}}$ and $\mathbf{b}(i \cdot x)_{\text {saltfilm }}$ of $316 \mathrm{~L}$ stainless steel in $1.2 \mathrm{M} \mathrm{LiCl}$ solutions of different $\mathrm{pH}$ (all values denoted as $(i \cdot x)$ are values for pit stability product under a salt film $\left.(i \cdot x)_{\text {saltfilm }}\right)$

by different authors [47, 48, 53-56]. Kuo and Landolt [53] determined the saturation concentration of ferrous ion at the metal surface to be $4.2 \mathrm{M}$ based on measurements of the limiting current density, which is very close to the saturation concentration of $4.25 \mathrm{M}$ reported for ferrous chloride in water [49]. A duplex film structure for the salt film on iron in ferrous chloride electrolyte in which the inner film is compact and anhydrous with the outer layer being porous and hydrated was proposed by Grimm et al. [54] and later by West et al. [55]. From their work on Fe-Cr alloys in ferrous chloride and sodium chloride electrolyte solutions, Grimm et al. [54] reported that ferrous chloride was the precipitated salt film with the limiting current density being controlled by the transport of ferrous ions.

It was shown earlier that for a given alloy, both $E_{\mathrm{rp}}$ and $(i$. $x)_{\text {saltfilm }}$ were independent of bulk $\mathrm{pH}$ in acidic and neutral electrolyte solutions. The effect of bulk chloride concentration on the repassivation potential was also rationalized earlier in terms of local cathodic reactions and mixed potential theory. The dependence of the pit stability product under a salt film on bulk chloride concentration was examined, with Fig. 11 showing the variation of $(i \cdot x)_{\text {saltfilm }}$ with bulk electrolyte chloride concentration for 304 and $316 \mathrm{~L}$. As indicated in the figure, the $(i \cdot x)_{\text {saltfilm }}$ value of both alloys decreased with increasing chloride concentration. All the data were fit using linear regression $\left(R^{2}=0.91\right)$, and the following relationship was obtained:

$$
(i \cdot x)_{\text {salffilm }}=-0.11 C_{b, C l}+0.9
$$

Under the assumptions that $\mathrm{Cl}^{-}$and the "stainless steel cation," $\mathrm{M}^{\mathrm{n}+}$, are the dominant ionic species and that ion migration effects are overwhelmed by diffusion, in order to preserve steady-state diffusion, the following flux condition must be satisfied:

$$
J_{C 1}=n J_{m}
$$

where $J_{\mathrm{Cl}}$ is the diffusion flux of chloride ions, $J_{\mathrm{m}}$ is the diffusion flux of stainless steel cation (metal ion), and $n$ is the valence of the stainless steel cation.

Because both fluxes occur over the same diffusion length, Fick's first law can be rewritten as follows:

$D_{C 1}\left(C_{s, C 1}-C_{1: C 1}\right)=n D_{m}\left(C_{s a t, m}-C_{m}\right)$

where $C_{\mathrm{s}, \mathrm{Cl}}$ is the surface concentration of chloride, $C_{\mathrm{b}, \mathrm{Cl}}$ is the bulk chloride concentration, $C_{s a t, m}$ is the saturation concentration of metal chlorides, while $D_{\mathrm{Cl}}$ and $D_{\mathrm{m}}$ are diffusion coefficient of the chloride ion and the stainless steel cation, respectively.

The expression for the diffusion-limited current density for the metal ion with a minor rearrangement is as follows:

$(i \cdot x)_{\text {saltfilm }}=F n D_{m}\left(C_{s a t, m}-C_{s}\right)$

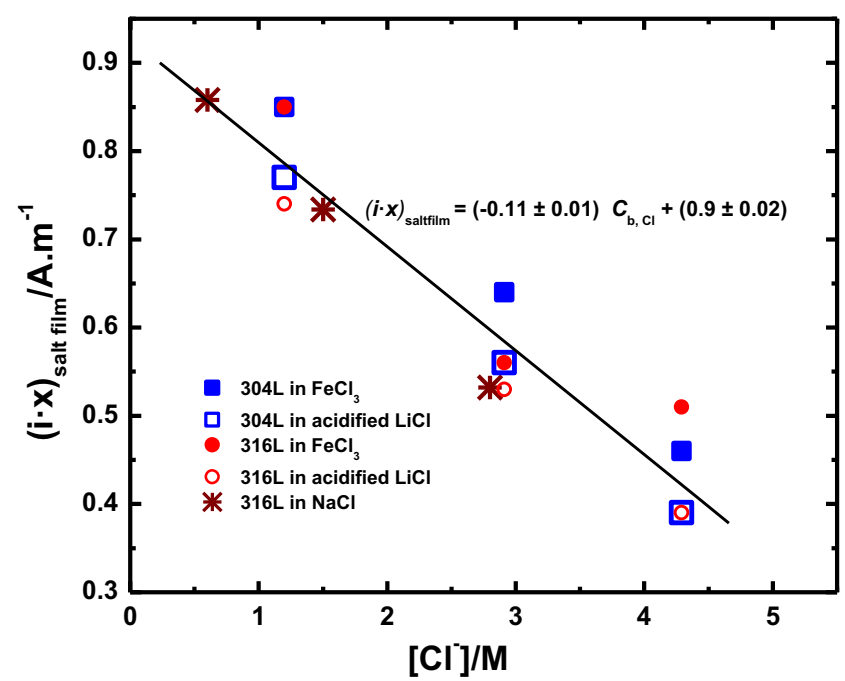

Fig. 11 Dependence of $(i \cdot x)_{\text {saltfilm }}$ of 304 and $316 \mathrm{~L}$ in different electrolytes on bulk chloride concentration, $C_{\mathrm{b}, \mathrm{Cl}}$, in different electrolytes 
Substituting Eq. 5 into Eq. 6:

$$
(i \cdot x)_{\text {salffim }}=F D_{C 1}\left(C_{s, C 1}-C_{b, C 1}\right)
$$

The electroneutrality condition dictates the following relationship between the concentrations of the metal cation and the chloride:

$C_{s, C 1}=n C_{s a t, m}$

Substituting for $C_{s, C 1}$ with $n C_{s a t, m}$ gives the following:

$$
(i \cdot x)_{\text {saltfilm }}=F D_{C 1}\left(n C_{\text {sat }, m}-C_{b, C 1}\right)
$$

Expanding Eq. 9:

$$
(i \cdot x)_{\text {saltfilm }}=F D_{C 1} n C_{s a t, m}-F D_{C 1} C_{s, C 1}
$$

Eq. 10 that results from above is of the form:

$$
(i \cdot x)_{\text {saltfilm }}=A-B C_{b, C 1}
$$

Therefore, the linear relationship of the pit stability product under a salt film with the bulk chloride concentration was rationalized as an alternative expression of the relationship between the diffusion fluxes of the metal cation and the chloride ion under steady-state conditions.

Stochiometric dissolution of the primary alloying components of 304 and $316 \mathrm{~L}$ (Fe, $\mathrm{Cr}, \mathrm{Ni}$ ) was assumed yielding values of $n=2.2$ and 2.245 which was then used to calculate the corresponding $D$. Based on Eqs. 3 and 10, the value of $D_{\mathrm{Cl}}$ was calculated first from the slope value. Once $D_{\mathrm{Cl}}$ was determined, it was used to calculate $C_{\mathrm{sat}, \mathrm{m}}$ from the intercept. In all of the calculations, the diffusion coefficient was assumed to be independent of bulk chloride concentration. These calculations resulted in the following values for the diffusion coefficient of the stainless steel cation and the concentration at saturation of the metal chlorides:

$$
\begin{aligned}
& D_{m, a v g}=9.2 \times 10^{-6} \mathrm{~cm}^{2} \mathrm{~s}^{-1} \\
& C_{s a t, m}=3.72 \mathrm{M}
\end{aligned}
$$

This value of $D_{\mathrm{m}}$ was seen to be comparable to values reported by Kuo and Landolt [53], Gaudet et al. [50], and Ernst and Newman [57].

Isaacs et al. [58] reported the in situ X-ray microprobe analysis of salt film during anodic dissolution of stainless steel in chloride solution where the beam intensities were used for quantitative determination the $\mathrm{Fe}, \mathrm{Ni}$, and $\mathrm{Cr}$ concentration in the salt film and solution in relation to the alloy composition of the austenitic stainless steel sample as shown in Table 2. The saturation concentration, $C_{\mathrm{sat}, \mathrm{m}}=3.72 \mathrm{M}$, determined in this work is $\approx 74 \%$ of the saturation concentration determined by Isaacs et al. [58].

Ernst and Newman [49] estimated the value of $C_{\mathrm{s}}$ to be $4.9 \mathrm{~m} \approx 4.35 \mathrm{M}$ (calculated using the density of saturated $\mathrm{FeCl}_{2}$ as $1.44 \mathrm{~g} \mathrm{~cm}^{-3}$ [58]) for 316 stainless steel at low $\mathrm{NaCl}$ concentration and a temperature of $30{ }^{\circ} \mathrm{C}$. These values are comparable to the $C_{\mathrm{s}}$ values calculated in $\mathrm{FeCl}_{3}$ and $\mathrm{LiCl}$ for the 304 and 316 L. Ernst and Newman [49] plotted the $D \cdot C$ as a function of bulk chloride concentration for $316 \mathrm{~L}$ in $\mathrm{NaCl}$ and $\mathrm{CaCl}_{2}$ at $30^{\circ} \mathrm{C}$, where $D$ referred to the diffusion coefficient of the stainless steel cation and $C$ denoted the concentration of the metal chlorides at the pit base. A linear relationship was observed by the authors, reproduced below:

This figure is similar to the $(i . x)_{\text {saltfilm }} \mathrm{vs}\left[\mathrm{Cl}^{-}\right]$plot in Fig. 11. Ernst and Newman [49] described the observed linearity as a coincidence. Laycock et al. [59] reported that the linearity could result from a fraction (56\%) of the chlorides in the salt film being present as complexed chlorides which act as a reservoir of chloride ions, thereby altering the salt film solubility through the common ion effect. However, their analysis did not provide an explanation for this particular fraction, other than the fact that this value fit the experimental data of Ernst and Newman [49]. In this work, we have shown below an alternative explanation for the observed linearity which follows from the previous discussion of $(i \cdot x)_{\text {saltfilm }}$ as a function of bulk chloride concentration. Rearranging Eq 1, the following relationship was obtained:

$D C_{s}=\frac{(i \cdot x)_{\text {saltfilm }}}{n F}+D C_{b u l k, C 1}$

Based on Eq. 12, a plot of $D C_{\mathrm{s}}$ vs $C_{\text {bulk, Cl }}$ would give $D$ from the slope and $(i \cdot x)_{\text {saltfilm }}$ from the intercept. From Fig. 11, assuming $6.25 \times 10^{-8}$ and $4 \times 10^{-8} \mathrm{~mol} \mathrm{~cm}^{-1} \mathrm{~s}^{-1}$ as intercepts for $D C_{\mathrm{s}}$ and $D C^{*}$, respectively, would provide corresponding

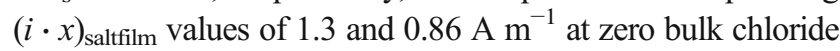
concentration. The value of $0.86 \mathrm{~A} \mathrm{~m}^{-1}$ obtained from the data of Ernst and Newman [49] in Fig. 12 is close to the $(i \cdot x)_{\text {saltfilm }}$ value of $0.9 \mathrm{~A} \mathrm{~m}^{-1}$ at zero bulk chloride concentration for $316 \mathrm{~L}$

Table 2 Concentration of $\mathrm{Fe}, \mathrm{Cr}$, and $\mathrm{Ni}$ in salt film and solution

\begin{tabular}{lllll}
\hline Element & $\begin{array}{l}\text { Alloy } \\
\text { (wt pct) }\end{array}$ & $\begin{array}{l}\text { Salt } \\
\text { (wt pct) }\end{array}$ & $\begin{array}{l}\text { Solutions } \\
\text { (wt pct) }\end{array}$ & $\begin{array}{l}\text { Molar } \\
\text { concentration }\end{array}$ \\
\hline $\mathrm{Fe}$ & $69.50 \pm 0.93$ & $20.87 \pm 5.71$ & $13.43 \pm 0.15$ & 3.46 \\
$\mathrm{Cr}$ & $17.37 \pm 0.61$ & $0.22 \pm 0.22$ & $3.88 \pm 0.22$ & 1.08 \\
$\mathrm{Ni}$ & $11.42 \pm 0.54$ & $1.34 \pm 0.18$ & $1.96 \pm 0.07$ & 0.48 \\
Total & & & & 5.02 \\
\hline
\end{tabular}

Table taken from Isaacs et al. [58] 
in $\mathrm{FeCl}_{3}$ and $\mathrm{LiCl}$ based on Eq. 3 in this work. Ernst and Newman [49] reported that the critical concentration of metal cation $C^{*}$ was approximately $60 \%$ of the saturation concentration, $C_{\mathrm{s}}$. The value of $60 \%$ of saturation as an upper bound for the critical concentration has been observed for $316 \mathrm{~L}$ from previous work [52] on the experimental validation of the maximum pit size model [60]. Using the intercept for $D C^{*}$ instead of the $D C_{\mathrm{s}}$ from Fig. 12 would therefore be reasonable for estimating the diffusion coefficient. This calculation resulted in a value of $1.53 \times$ $10^{-5} \mathrm{~cm}^{2} \mathrm{~s}^{-1}$ for the diffusion coefficient of the stainless steel cation, with $C_{\mathrm{s}}=4.35 \mathrm{M}$ as considered originally by Ernst and Newman [49], which was seen to be comparable to the diffusion coefficient value determined in this work. The difference observed in the two values may be attributed to the fact that Ernst and Newman [49] performed their experiments at a temperature of $30^{\circ} \mathrm{C}$, whereas our results are for a temperature of $25^{\circ} \mathrm{C}$.

Thus, by assuming that the diffusion coefficient was independent of concentration and neglecting the effects of ion migration, a good estimate of $D$ and $C_{S}$ was obtained experimentally from a simple plot of pit stability product under a salt film as a function of bulk chloride concentration.

$E_{\mathrm{rp}}$ or $E^{\oplus} ?$

For the ferric chloride experiments, one might be concerned that the value of $E_{\mathrm{rp}}$ measured was affected by the ferric/ferrous redox couple. However, evidence from literature as well as results from this work showed otherwise. The reversible potential of $\mathrm{Fe}^{3+} \mid \mathrm{Fe}^{2+}$ in solutions of $\mathrm{pH}$ less than about 2.5 has been shown to be independent of $\mathrm{pH}$ and is equal to $+0.771 \mathrm{~V}$ vs NHE $(+0.531 \mathrm{~V}$ vs SCE) [61]. In related work, Woldemedhin et al. [52] measured the cathodic behavior of $304 \mathrm{~L}$ and $316 \mathrm{~L}$ in

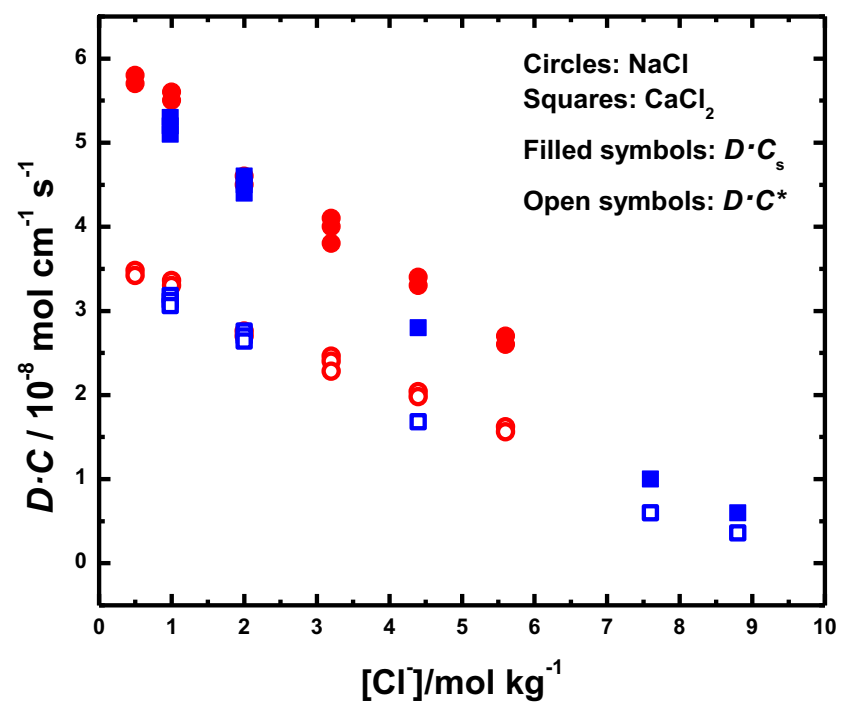

Fig. 12 Plot of $D \cdot C$ versus bulk chloride concentration from onedimensional pit experiments on $316 \mathrm{~L}$ in $\mathrm{NaCl}$ and $\mathrm{CaCl}_{2}$ solutions at $30{ }^{\circ} \mathrm{C}$ (data redrawn from the work of Ernst and Newman [49])

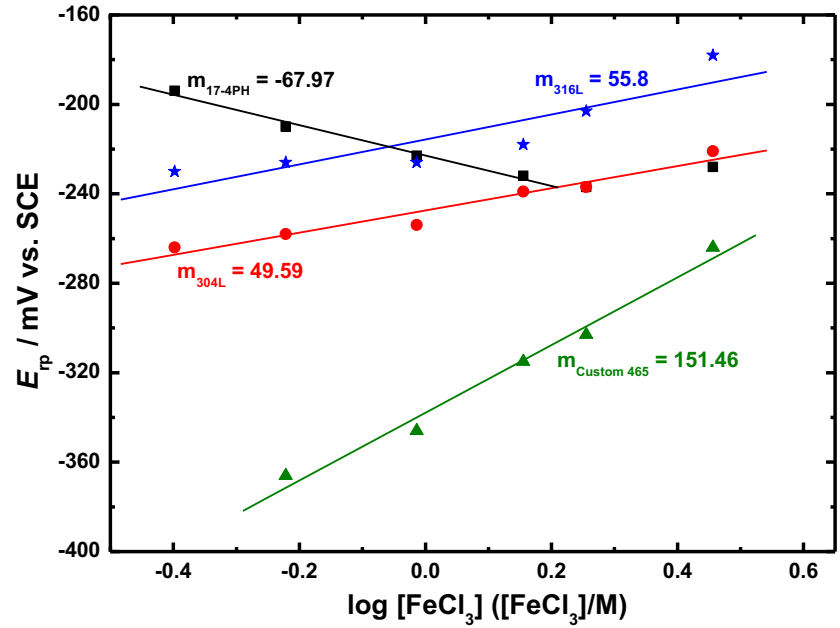

Fig. 13 Variation of repassivation potential of the four steel samples versus bulk $\mathrm{FeCl}_{3}$ concentration

ferric sulfate solutions of low $\mathrm{pH}$. The open circuit potential of the stainless steels measured was very close to $+0.5 \mathrm{~V}$ vs SCE in this chloride-free solution, indicating that they were acting as inert electrodes. The values of the repassivation potentials measured in this work were more than $600 \mathrm{mV}$ more electronegative than the reversible potential; therefore, the measured $E_{\mathrm{rp}}$ could not have been obscured by the redox potential of the $\mathrm{Fe}^{3+} \mid \mathrm{Fe}^{2+}$ couple. In addition, as seen in Fig. 13, the dependences of repassivation potentials on ferric chloride concentration showed different trends for the various stainless steels. If the measured repassivation potentials were actually redox potentials, all the dependences would have been the same.

\section{Conclusions}

Using the artificial pit electrode, the kinetics of pitting corrosion of the stainless steels 304, $316 \mathrm{~L}, 17-4 \mathrm{PH}$, and Custom 465 were studied in bulk electrolyte solutions of ferric chloride and lithium chloride. After growing one-dimensional pits of different depths potentiostatically, the repassivation potential, $E_{r p}$ of the $304 \mathrm{~L}, 316 \mathrm{~L}, 17-4 \mathrm{PH}$, and Custom 465 steel samples were determined from the subsequent cathodic polarization scans. At each pit depth, the potential at which the current changed polarity during the polarization scan was taken as the repassivation potential of that alloy for that depth. The repassivation potentials of the steels were determined in ferric chloride and lithium chloride solutions having different concentration and $\mathrm{pH}$. The repassivation potential of all the steel samples reached a plateau value after sufficiently large amounts of charge had been passed. This potential where the repassivation potential is independent of charge density (and consequently, pit depth) was taken as true repassivation potential value of the stainless steel in the environment under consideration. The pit stability products under a salt film, $(i$. 
$x)_{\text {saltfilm }}$ of the stainless steels were also determined from the same experiments. The plot of the value of the current density plateau versus the reciprocal of the pit depth (calculated using Faraday's law) showed a linear relationship, thus proving that the process was diffusion limited under a salt film. The slope of this the linear fit provided the value of the pit stability product under a salt film. These experiments were performed in both electrolytes, in different chloride concentrations as well as $\mathrm{pH}$ values. In this manner, the effect of environmental factors on the two key kinetic parameters- $E_{\mathrm{rp}}$ and $(i \cdot x-$ )$_{\text {saltfilm }}$-were studied using results derived from the same experiment.

The repassivation potential increased with increasing chloride concentration for 304, $316 \mathrm{~L}$, and Custom 465 steel samples in ferric chloride solutions, unlike $17-4 \mathrm{PH}$ where its repassivation potential decreased with increasing chloride concentration. Contrary to the results in ferric chloride solutions, the repassivation potentials of $304 \mathrm{~L}$ and $316 \mathrm{~L}$ determined in lithium chloride solutions, having the same chloride concentration and $\mathrm{pH}$ as the ferric chloride solutions, decreased with increasing bulk chloride concentration. The difference in repassivation potential between the two solutions was negligible at lower chloride concentrations but increased at the highest chloride concentration. A first attempt at rationalizing the observed behavior of $E_{\mathrm{rp}}$ across bulk electrolyte concentration was made using mixed potential theory. It was recognized that although such rationalization explained the results for $316 \mathrm{~L}$ and $17-4 \mathrm{PH}$, further improvements were necessary to extend it to the results for $304 \mathrm{~L}$ and Custom 465 . The $(i \cdot x)_{\text {saltfilm }}$ value of all the stainless steels decreased with increasing chloride concentration, which was explained as a result lower salt film solubility and increased viscosity at higher concentration. The $\mathrm{pH}$ of the bulk solution was seen to have no effect on $E_{\mathrm{rp}}$ and $(i \cdot x)_{\text {saltfilm. }}$. The pit stability product under a salt film was seen to be linearly related to the bulk chloride concentration. These last two observations indicated that the pit solution chemistry was similar across the different electrolytes studied. Results from the rationalization of this phenomenology were used to estimate the diffusion coefficient of the stainless steel cation and the saturation concentration of the metal chloride salts within the pit, which compared well with the values reported in literature.

Open Access This article is distributed under the terms of the Creative Commons Attribution License which permits any use, distribution, and reproduction in any medium, provided the original author(s) and the source are credited.

\section{References}

1. Galvele JR (1976) Transport processes and the mechanism of pitting of metals. J Electrochem Soc 123:464-474
2. Galvele JR (1981) Transport processes in passivity breakdown-II. Full hydrolysis of the metal ions. Corros Sci 21:551-579

3. Gravano SM, Galvele JR (1984) Transport processes in passivity breakdown-III. Full hydrolysis plus ion migration plus buffers. Corros Sci 24:517-534

4. Pourbaix M, Klimzack-Mathieiu L, Mertens C et al (1963) Potentiokinetic and corrosimetric investigations of the corrosion behaviour of alloy steels. Corros Sci 3:239-259

5. Steigerwald RF (1966) Effect of $\mathrm{Cr}$ content on pitting behavior of FeCr alloys. Corrosion 22:107-112

6. France WD, Greene ND (1970) Comparison of chemically and electrolytically induced pitting corrosion. Corrosion 26:1-4

7. Wilde BE, Williams E (1970) On the correspondence between electrochemical and chemical accelerated pitting corrosion tests. J Electrochem Soc 117:775-779

8. Wilde BE, Williams E (1971) The use of current/voltage curves for the study of localized corrosion and passivity breakdown on stainless steels in chloride media. Electrochim Acta 16:1971-1985

9. Wilde BE (1972) A critical appraisal of some popular laboratory electrochemical tests for predicting the localized corrosion resistance of stainless alloys in sea water. Corrosion 28:283-291

10. Wilde BE (1974) On pitting and protection potentials: their uses and possible misuse for predicting localized corrosion resistance of stainless alloys in halide media. In: Staehle RW, Brown BF, Kruger J, Agarwal A (eds) Localized corrosion. NACE, Houston, pp 342-352

11. Nakayama T, Sasa K (1976) Effect of ultrasonic waves on the pitting potentials of 18-8 stainless steel in sodium chloride solution. Corros Eng Sci Technol 32:283-285

12. Sugimoto K, Asano K (1990) Analysis of localized corrosion on stainless steel by microcomplex $\mathrm{pH}-\mathrm{pCl}$ electrode. In: Isaacs HS, Bertocci V, Kruger J, Smialowska S (eds) Advances in localized corrosion. NACE, Houston, pp 375-379

13. Yashiro H, Tanno K (1990) The effect of electrolyte composition on the pitting and repassivation behavior of AISI 304 stainless steel at high temperature. Corros Sci 31:485-490

14. Thompson NG, Syrett BC (1992) Relationship between conventional pitting and protection potentials and a new, unique pitting potential. Corrosion 48:649-659

15. Sridhar N, Cragnolino GA (1993) Applicability of repassivation potential for long-term prediction of localized corrosion of alloy 825 and type 316 L stainless steel. Corrosion 49:885-894

16. Sridhar N, Cragnolino GA, Dunn DS (1993) Experimental investigations of localized corrosion of high-level waste container materials. Technical report CNWRA 93-004, Center for Nuclear Waste Regulatory Analyses, San Antonio, TX

17. Frankel GS, Stockert L, Hunkeler F, Boehni H (1987) Metastable pitting of stainless steel. Corrosion 43:429-436

18. Pistorius PC, Burstein GT (1992) Metastable pitting corrosion of stainless steel and the transition to stability. Philos Trans Phys Sci Eng 341:531-559

19. Williams DE, Stewart J, Balkwill PH (1994) The nucleation, growth and stability of micropits in stainless steel. Corros Sci 36:1213-1235

20. Laycock NJ, Newman RC (1997) Localised dissolution kinetics, salt films and pitting potentials. Corros Sci 39:1771-1790

21. Moayed MH, Newman RC (2006) The relationship between pit chemistry and pit geometry near the critical pitting temperature. $\mathrm{J}$ Electrochem Soc 153:B330-B335

22. Beck TR (1973) Pitting of titanium: II. One-dimensional pit experiments. J Electrochem Soc 120:1317-1324

23. Harris DC (1991) quantitative chemical analysis. W. H, Freeman and Company, New York

24. Lillard RS, Jurinski MP, Scully JR (1994) Crevice corrosion of alloy 625 in chlorinated ASTM artificial ocean water. Corrosion 50:251265 
25. Sridhar N, Dunn DS (1994) Effect of applied potential on changes in solution chemistry inside crevices on type 3041 stainless steel and alloy 825. Corrosion 50:857-872

26. Zuo Y, Fu S (1998) Surface roughness and metastable pitting of amorphous nickel alloy. Corrosion 54:313-316

27. Ramgopal T, Frankel GS (2001) Role of alloying additions on the dissolution kinetics of aluminum binary alloys using artificial crevice electrodes. Corrosion 57:702-711

28. Dunn DS, Pan Y-M, Yang L, Cragnolino GA (2005) Localized corrosion susceptibility of alloy 22 in chloride solutions: part $1-$ millannealed condition. Corrosion 61:1078-1085

29. Sourisseau T, Chauveau E, Baroux B (2005) Mechanism of copper action on pitting phenomena observed on stainless steels in chloride media. Corros Sci 47:1097-1117

30. Hayes JR, Gray JJ, Szmodis AW, Orme CA (2006) Influence of chromium and molybdenum on the corrosion of nickel-based alloys. Corrosion 62:491-500

31. Yashiro H, Tanno K, Hanayama H, Miura A (1990) Effect of temperature on the crevice corrosion of type 304 stainless steel in chloride solution up to $250{ }^{\circ} \mathrm{C}$. Corrosion 46:727-733

32. Cragnolino GA, Sridhar N (1991) Localized corrosion of a candidate container material for high-level nuclear waste disposal. Corrosion 47:464-472

33. Dunn DS, Cragnolino GA, Sridhar N (2000) An electrochemical approach to predicting long-term localized corrosion of corrosionresistant high-level waste container materials. Corrosion 56:90-104

34. Kehler BA, Ilevbare GO, Scully JR (2001) Crevice corrosion stabilization and repassivation behavior of alloy 625 and alloy 22 . Corrosion 57:1042-1065

35. Newman RC, Ajjawi MAA (1986) A microelectrode study of the nitrate effect on pitting of stainless-steels. Corros Sci 26:1057-1063

36. Brossia CS, Kelly RG (1998) Occluded solution chemistry control and the role of alloy sulfur on the initiation of crevice corrosion in type 304ss. Corros Sci 40:1851-1871

37. Anderko A, Sridhar N, Dunn DS (2004) A general model for the repassivation potential as a function of multiple aqueous solution species. Corros Sci 46:1583-1612

38. Li L, Sagüés AA (2004) Chloride corrosion threshold of reinforcing steel in alkaline solutions - effect of specimen size. Corrosion 60: 195-202

39. Moayed MH, Newman RC (2006) Deterioration in critical pitting temperature of $904 \mathrm{~L}$ stainless steel by addition of sulfate ions. Corros Sci 48:3513-3530

40. Tester JW, Isaacs HS (1975) Diffusional effects in simulated localized corrosion. J Electrochem Soc 122:1438-1445

41. Buzza DW, Alkire RC (1995) Growth of corrosion pits on pure aluminum in $1 \mathrm{M} \mathrm{NaCl}$. J Electrochem Soc 142:1104-1111

42. Frankel GS, Scully JR, Jahnes CV (1996) Repassivation of pits in aluminum thin films. J Electrochem Soc 143:1834-1840

43. Evans KJ, Yilmaz A, Day SD et al (2005) Using electrochemical methods to determine alloy 22 's crevice corrosion repassivation potential. JOM 57:56-61
44. Tormoen G, Sridhar N, Anderko A (2010) Localised corrosion of heat treated alloys Part I - Repassivation potential of alloy 600 as function of solution chemistry and thermal aging. Corros Eng Sci Technol 45:155-162

45. Okada T (1984) Considerations of the stability of pit repassivation during pitting corrosion of passive metals. J Electrochem Soc 131: 1026-1032

46. Jones DA (1996) Principles and prevention of corrosion. Prentice Hall, Upper Saddle River

47. Kuo HC, Landolt D (1976) Galvanostatic transient study of anodic film formation on iron in concentrated chloride media. Corros Sci 16: 915-922

48. Kuo HC, Nobe K (1978) Electrodissolution kinetics of iron in chloride solutions: VI. Concentrated acidic solutions. J Electrochem Soc $125: 853-860$

49. Ernst P, Newman RC (2007) Explanation of the effect of high chloride concentration on the critical pitting temperature of stainless steel. Corros Sci 49:3705-3715

50. Gaudet GT, Mo WT, Hatton TA et al (1986) Mass transfer and electrochemical kinetic interactions in localized pitting corrosion. AIChE J 32:949-958

51. Steinsmo U, Isaacs HS (1993) The dissolution and repassivation kinetics of Fe-Cr alloys in pit solutions. Corros Sci 35:83-88

52. Woldemedhin MT, Shedd ME, Kelly RG (2014) Evaluation of the maximum pit size model on stainless steels under thin film electrolyte conditions. J Electrochem Soc 161:E3216-E3224

53. Kuo HC, Landolt D (1975) Rotating disc electrode study of anodic dissolution or iron in concentrated chloride media. Electrochim Acta 20:393-399. doi:10.1016/0013-4686(75)90022-5

54. Grimm RD, West AC, Landolt D (1992) AC impedance study of anodically formed salt films on iron in chloride solution. J Electrochem Soc 139:1622-1629

55. West AC, Grimm R-D, Landolt D et al (1992) Electrohydrodynamic impedance study of anodically formed salt films on iron in chloride solutions. J Electroanal Chem 330:693-706

56. Grimm R-D, Landolt D (1994) Salt films formed during mass transport controlled dissolution of iron-chromium alloys in concentrated chloride media. Corros Sci 36:1847-1868

57. Ernst P, Newman RC (2002) Pit growth studies in stainless steel foils. I. Introduction and pit growth kinetics. Corros Sci 44:927-941

58. Isaacs HS, Cho J-H, Rivers ML, Sutton SR (1995) In situ x-ray microprobe study of salt layers during anodic dissolution of stainless steel in chloride solution. J Electrochem Soc 142:1111-1118

59. Laycock NJ, Krouse DP, Ghahari SM et al (2012) Localized dissolution kinetics from fast in situ radiography of propagating pits in stainless steel and implications for modeling pitting corrosion over long time-scales. ECS Trans 41:3-16

60. Chen ZY, Kelly RG (2010) Computational modeling of bounding conditions for pit size on stainless steel in atmospheric environments. J Electrochem Soc 157:C69-C78

61. Heusler KE (1982) The electrochemistry of iron. In: Bard AJ (ed) Encyclopedia of electrochemistry of the elements vol IX A. Marcel Dekker, Inc., New York, p 229 